\title{
Analysis of coronary collaterals in ischaemic heart disease by angiography during pacing induced ischaemia ${ }^{1}$
}

\author{
M. H. Frick, M. Valle, O. Korhola, E. Riihimäki, and M. Wiljasalo \\ From the Cardiovascular Laboratory, First Department of Medicine, and from the First Department of Radio- \\ logy, University Central Hospital, Helsinki, Finland
}

Studies were made using ordinary selective coronary angiography and angiography during ischaemia produced by right atrial pacing, on a series of 41 patients with ischaemic heart disease, to examine the response of the collaterals to the ischaemia stimulus. Regional myocardial perfusion was determined under the same circumstances by measuring regional ${ }^{133} \mathrm{Xenon}$ washout curves.

No collaterals were found in 8 patients, none of whom demonstrated collaterals when angiography was repeated during ischaemia. Eleven of the 33 patients with prepacing collaterals (33\%) responded to ischaemia with an increase in the collaterals, 16 patients (49\%) showed no change, 5 patients (15\%) showed a decrease in the collaterals, and one patient exhibited a bidirectional change. Regional myocardial perfusion responses closely paralleled the angiographic changes, yielding suggestive evidence that the collaterals were intimately involved in the enhancement of the flow.

Despite different collateral and flow responses to ischaemia, the data on exercise tolerance, left ventricular end-diastolic pressure, ejection fraction, prevalence of left ventricular asynergy, and the topographic relation between asynergy and collaterals, were largely similar. The data show that in some patients the collateral circulation reacts to ischaemia by enhancement, but the functional significance of this response is obscure.

Coronary collateral circulation has been the subject of great interest for decades (Blumgart, Schlesinger, and Davis, 1940; Zoll, Wessler, and Schlesinger, 1951; Baroldi, Mantero, and Scomazzoni, 1956; Bloor and Liebow, 1965; Fulton, 1965; Paulin, 1967; Gensini and Da- Costa, 1969; James, 1970). It is now generally accepted that coronary collaterals are congenitally determined. Large differences in both the number and location of these vessels have been found in mammalian species (Schaper, 1971), but it is not known whether there is such an inherited variation in man. Angiographic studies of ischaemic heart disease have revealed subgroups of patients with varying collateral patterns which can be roughly grouped as follows: 1) no collaterals, 2) some collaterals, and 3) rich collateral networks. There is conflicting evidence relating to the

Received 7 April 1975.

'Supported by grants from the Finnish State Council for Medical Research, the Finnish Heart Association, and the E. Aaltonen Foundation. functional significance of these different patterns with regard to their role in preventing ischaemia, influencing left ventricular function, and modifying prognosis (Demany, Tambe, and Zimmerman, 1967; Helfant, Kemp, and Gorlin, 1970; MartinezRios et al., 1970; Tuna and Amplatz, 1970; Helfant, Vokonas, and Gorlin, 1971; Miller et al., 1971; Helfant and Gorlin, 1972; Miller et al., 1972; Moberg, Webster, and Sones, 1972; Levin et al., 1973; Banka, Bodenheimer, and Helfant, 1974; Carroll, Verani, and Falsetti, 1974; Handa et al., 1974; Lavine et al., 1974; Williams et al., 1974).

When there is adequate backflow during selective coronary angiography, the radio-opaque material is not forced under pressure into the high resistance coronary arterial circulation, but is merely carried along with the blood stream. Therefore, only collaterals carrying flow are visualized. An additional factor is the resolution power of the current radiographic techniques, limiting adequate visualization to vessels of $100 \mu$ or more. Of the various 
mechanisms which may establish collateral flow in ischaemic heart diseases, effective pressure gradients created by the luminal obstructions evidently play the major role. This is illustrated by the disappearance of the collaterals after successful bypass surgery (Valle et al., 1975). During coronary angiography, ischaemia is avoided if possible. Consequently, visualization of the collaterals may be incomplete in the absence of the postobstruction vasodilatation caused by ischaemia. Thus, conclusions drawn from ordinary coronary angiograms do not necessarily apply to the circumstances prevailing during ischaemia.

The present study compares collateral circulation demonstrated by routine coronary angiography and by angiography during ischaemia induced by right atrial pacing. Additional information was obtained by determining the regional myocardial blood flow under the same circumstances.

\section{Subjects and methods}

Forty-one patients who were potential candidates for coronary bypass surgery were studied. The age range was from 29 to 60 , with a mean of 47 years. There were 36 men and 5 women. All had angina pectoris responding to sublingual nitroglycerin, but despite treatment with beta-adrenergic blocking agents were unable to work. Each patient had a routine physical examination and biochemical tests, routine chest $x$-ray with heart volume measurements (Jonsell, 1939), and a maximal exercise test on an electrically-braked bicycle ergometer (ElemaSchönander, Sweden). In this test the patient pedalled in the sitting position, and the load was gradually increased without intervening pauses up to the subjective maximum, i.e. the development of angina and/or dyspnoea, requiring the test to be stopped. The electrocardiogram was continuously monitored and recorded once a minute. The exercise tolerance was measured as the total work (TW) in kiloNewton-metres $(\mathrm{kNm})$ representing all the loads accomplished multiplied by the respective times in minutes, as the maximal tolerated load (MaxL, $\mathrm{kNm} / \mathrm{min}$ ), and as the maximal heart rate (MaxHR, beats $/ \mathrm{min}$ ). Treatment with beta-adrenergic blocking drugs was stopped at least one week before the exercise test. Horizontal or downward-sloping ST segment depression occurred in all patients, but was not analysed because some patients were taking digitalis (Frick, Virtanen, and Sävelä, 1972).

The angiographic studies were begun by a left ventricular cineangiogram in the right anterior oblique position using a pig-tail catheter inserted percutaneously, and injection of $60 \mathrm{ml}$ Urografin $(60 \%)$. This was followed by selective coronary angiography by Judkins' technique. In positioning the catheters in the coronary ostia, special care was taken to avoid occlusion, and adequate backflow was ensured before injection. Both the left and right coronary arteries were injected in three different projections as previously described (Valle,
1973). An Arriflex cine camera was used at a speed of 80 frames/s. In addition, $35 \times 35 \mathrm{~cm}$ films were exposed in two projections for each coronary artery. The total number of selective injections was thus 5 per artery. If the patient did not have angina or had only transient and mild pain, he was asked to repeat the study during angina to be caused by speeding up the heart; consent was obtained from every subject. In our laboratory the pacing technique has remained essentially the same as originally described (Sowton et al., 1967), consisting of a gradual increase in heart rate until the development of angina and/or dyspnoea, with ischaemic ST segment changes. The details of this technique combined with coronary angiography have been described (Frick et al., 1974). In brief, a selective injection was made during ischaemia into the coronary artery which gave rise to the collaterals seen on the prepacing angiograms, and cine filming was repeated. Thereafter a second selective injection was made and $35 \times 25 \mathrm{~cm}$ films were exposed at a rate of 5 per injection. If the collaterals originated from two arteries, both of these were injected. The amount of contrast material was kept constant in all the injections. The time interval between the prepacing injections and the injections during ischaemia varied frcm 3 to 10 minutes according to the angina threshold of the patients. The motion blur in the large films caused by the rapid heart action was largely eliminated by exposure times of 10 to $16 \mathrm{~ms}$ (and lately of only $2 \mathrm{~ms}$ ) using the rare-earth oxysulphide screens for large films (3 M-system). Subjective discomfort lasted approximately one minute and the pain was rapidly relieved by stopping pacing. No complications occurred, and the customary bradycardia after the injections was easier to manage with the aid of pacing.

After the coronary angiography, a Paulin catheter was placed into the aortic root just above the aortic valves for the injection of ${ }^{133}$ Xenon. A bolus of 30 to $50 \mathrm{mCi}$ ${ }^{133}$ Xenon was injected in $10 \mathrm{ml}$ physiological saline with an Elema-Schönander Cisal injector at a pressure of $5 \mathrm{~atm}$. A Nuclear-Chicago Pho/Gamma III camera connected to an Intertechnique Tridac analyser was used. The gamma images were recorded in digital form in a $64 \times 64$ matrix at a rate of one per second and simultaneously on magnetic tape which could be replayed on the memory system of the analyser. The activity was recorded for five minutes, after which right atrial pacing was repeated to induce ischaemia, when a second ${ }^{133}$ Xenon injection was made followed by data processing similar to that performed after the first injection. The patient was kept in essentially the same position during the whole procedure. From the gamma image four different areas were analysed for myocardial flow: 1) the whole heart, 2) a possible perfusion defect and 3) two reference areas in the vicinity of the perfusion defect (Fig. 1). For the calculation of the washout curve for each selected region, a computer programme in Algol was applied. This finds the highest disappearance constant for 25 seconds from the time-activity curves starting 10 seconds after the injection, as previously described in detail (Korhola, 1974). The time-activity curve analysis system consisted of a Datapoint remote terminal to a time-shared Univac 1108 computer. 


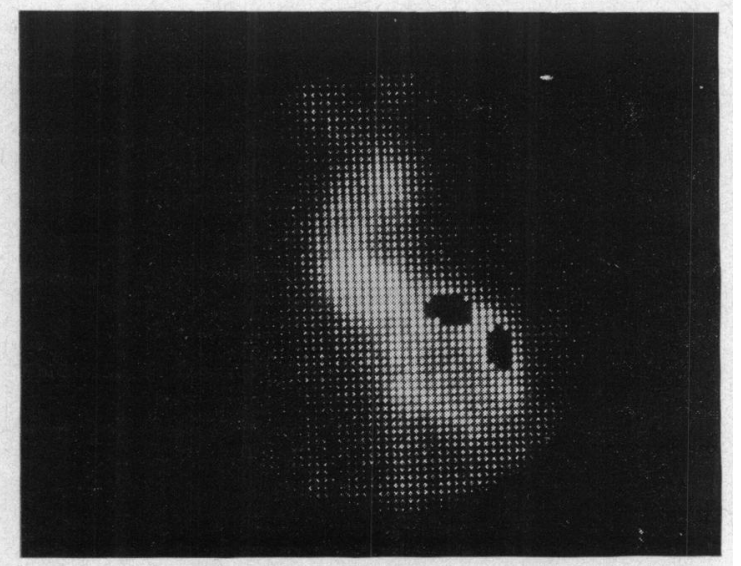

FIG. 1 Gamma image showing a perfusion defect in the anterior wall. The black spots demonstrate areas selected by a light pen for detailed analysis of regional myocardial perfusion.

The left ventricular cineangiograms were analysed for regional motion abnormalities (Herman et al., 1967), and ejection fraction was calculated using percentage changes in the diameter from multiple axes if required (Lewis and Sandler, 1971).

The luminal obstructions in the coronary arteries were estimated as percentages. To facilitate the statistical comparison of different subgroups the scoring system of the European Multicentre Study of aorto-coronary bypass surgery was adopted: $0=$ no obstruction, $1=<25$ per cent, $2=25$ to 50 per cent, $3=51$ to 75 per cent, $4=$ subtotal, and $5=$ total obstruction. The total score for each patient was used.

In comparing the prepacing and pacing angiograms, both the $35 \times 35 \mathrm{~cm}$ and the cine films were used and the comparisons were made in the same phase of the cardiac cycle. Attention was paid to the calibre of the large epicardial arteries and to the collaterals, which were classified as follows: $0=$ no collaterals, $1=$ few collaterals without opacification of postobstructive segments, $2=$ collaterals with opacification of a distal segment, and $3=$ excellent filling of a postobstructive segment allowing the assessment of the degree of narrowing. The resolution power of the angiographic unit permitted analysis of vessels of $100 \mu$ or more. In assessing the effect of ischaemia induced by pacing, the following criteria were used: no change, increase in numbers, increase in calibre, decrease in numbers, and decrease in calibre, of collaterals. A change was accepted when there was agreement between three independent observers. Visual observations of a change in the calibre of the large epicardial arteries were corroborated by micrometer measurements at equidistant points. The rapid heart rate during pacing was evident in the cine films and excluded a 'blind' analysis of the changes. Student's t-test (one-tailed) was used in determining the significance of the difference of sample means.

\section{Comments on methods}

Depending on whether the collaterals originated from the left or from the right coronary artery, 5 or 10 selective injections were made in the prepacing state before the injections during pacing-induced ischaemia. It could be argued that these previous injections resulted in the collateral pattern observed during ischaemia. Analysis of the angiograms obtained during repeated prepacing injections disclosed no systematic difference from the first to the last injection; the collateral pattern remained both quantitatively and qualitatively the same as it appeared in the first exposure. The angiographic studies were begun by an injection of $60 \mathrm{ml}$ Urografin into the left ventricle. The circulatory effects of angiography have been amply documented, and have also been observed in our laboratory (Frick, Heikkilä, and Luomanmäki, 1970). It is conceivable that the almost invariable rise in left ventricular end-diastolic pressure (LVEDP) persisted throughout the study, with added peaks caused by the selective intracoronary injections. The aortic pressure was constantly monitored through the coronary catheters but was not routinely recorded. There were no hypotensive episodes requiring treatment. It is known that little or no change in aortic pressure occurs during right atrial pacing (Sowton et al., 1967; Frick, 1972), making it highly unlikely that this plays a major role in the ischaemic response.

Except in cases with no prepacing collaterals, only the arteries from which the collaterals arose were injected during ischaemia. This was done to lessen the duration of angina, but as a result limited data were obtained on the response to ischaemia of the contralateral artery from which no collaterals arose on the prepacing angiogram. The ideal approach would have been simultaneous selective injections into both left and right coronary arteries.

The regional myocardial flow was determined to obtain supporting data on the functional significance of the response of the collaterals to ischaemia. A detailed analysis of regional myocardial flow in multiple areas is beyond the scope of this paper which is concerned with the demonstration of the dynamic properties of the collaterals. Yet it is essential to understand that a perfusion defect in a scintigram or diffuse heterogeneity of the uptake of the tracer in a particular area can be caused by a reduced flow or diminished viable muscle mass or both simultaneously. Sometimes even an increased flow can be detected in a 'cold spot' resulting from flow via large non-nutrient epicardial arteries. Viable muscle mass did not change between scintigrams made before and during the ischaemia, and the problem encountered in the present study was the difficulty of measuring the 'true' myocardial flow. The present technique assesses the highest flow component and the changes induced by ischaemia in each area. Consequently, the main emphasis in the analysis was on changes in flow rather than absolute values.

An additional difficulty in gamma imaging of the heart lies in the fact that the image is dominated by the anterior wall, the inferior wall being perpendicular to the axis of detection. This has led, for example, to a poor 
correlation between inferior wall asynergy and data from gamma imaging (Korhola et al., 1975). In the present series gamma imaging was performed on 30 patients. Only two patients had significant lesions in either the left circumflex or the right coronary artery without a concomitant obstruction in the anterior descending artery but both these patients had a cold spot in the anterior wall, and could be analysed in the same way as the other patients.

\section{Results}

\section{Angiographic data}

There were 8 patients without collaterals in the prepacing angiograms. Three of these had entirely normal coronary arteries and normal contraction patterns of the left ventricle. Two had an isolated 50 per cent stenosis in the left anterior descending artery with normal left ventricular contraction in one, and apical and low anterior hypokinesia in the other. There was also one patient with 90 per cent stenosis in the left anterior descending and 50 per cent stenosis in the right coronary artery (apical akinesia), one patient with 25 per cent stenosis in the right coronary artery (inferior hypokinesia), and one patient with 75 per cent stenosis in the left circumflex and 50 per cent stenosis in the right coronary artery (normal left ventricle). The clinical characteristics are given in Table 1. None of these patients showed collaterals when paced to ischaemia, but in one patient the calibre of the left anterior descending artery was reduced and in three the calibre of both the left anterior descending artery and the left circumflex was increased. Four patients showed no change in this respect.

Thirty-three patients had collaterals in prepacing angiograms. Pacing to ischaemia resulted in three different responses: 1) increase in collaterals, 2) no change, and 3) decrease in collaterals. In the description to follow these groups are labelled positive responders, nonresponders, and negative responders. One patient exhibited a bidirectional change and is analysed separately.

Positive responders This group consisted of 11 patients, 33 per cent of those with collaterals. In all patients the collaterals were feeding segments beyond total occlusions. In 8 patients left ventricular asynergy was detected and was topographically related to the area distal to occlusion and to the site of collaterals; in 2 patients asynergy was absent at the site of collaterals; and in 1 patient with total occlusions in all three arteries akinesia was observed in an apical area not supplied by collaterals, but was absent in the inferior wall supplied by collaterals from the left anterior descending artery and proximal right coronary artery.

In the prepacing angiogram 7 patients had class 2 collaterals; in 2 of these patients, collaterals remained in the same class but increased in number, and in 5, they increased to class 3 (Fig. 2). Four patients had class 3 collaterals which increased in calibre and in number. In this group 1 patient showed a clear widening of the left anterior de-

TABLE 1 Clinical features

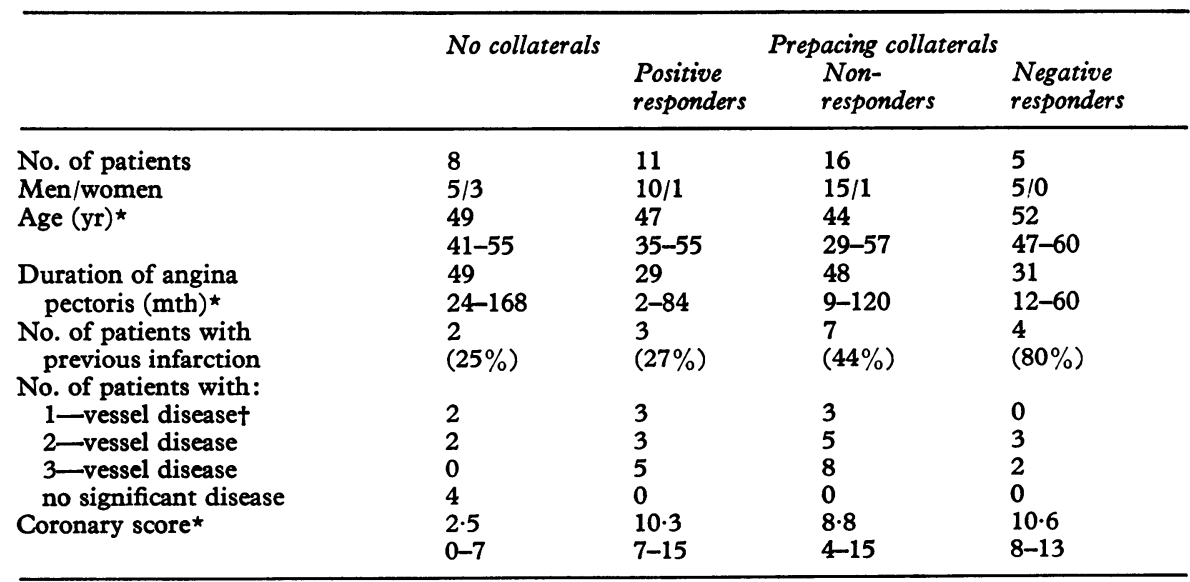

*Mean and range.

†50 per cent obstruction or more. 
190 Frick, Valle, Korhola, Riihimäki, and Wiljasalo

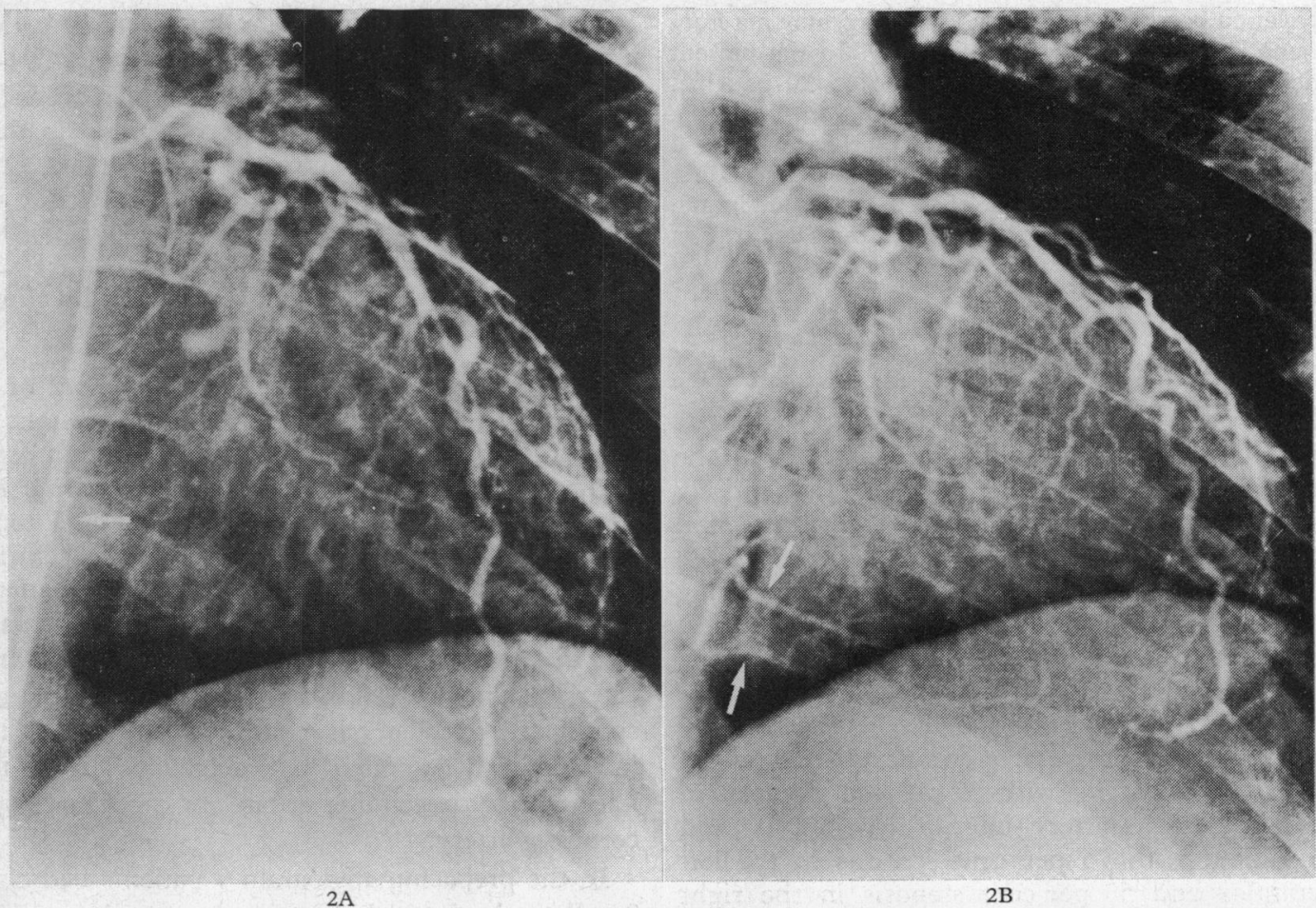

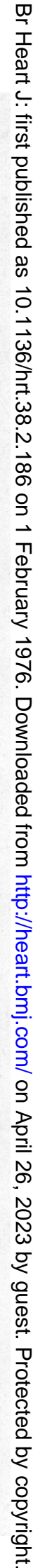

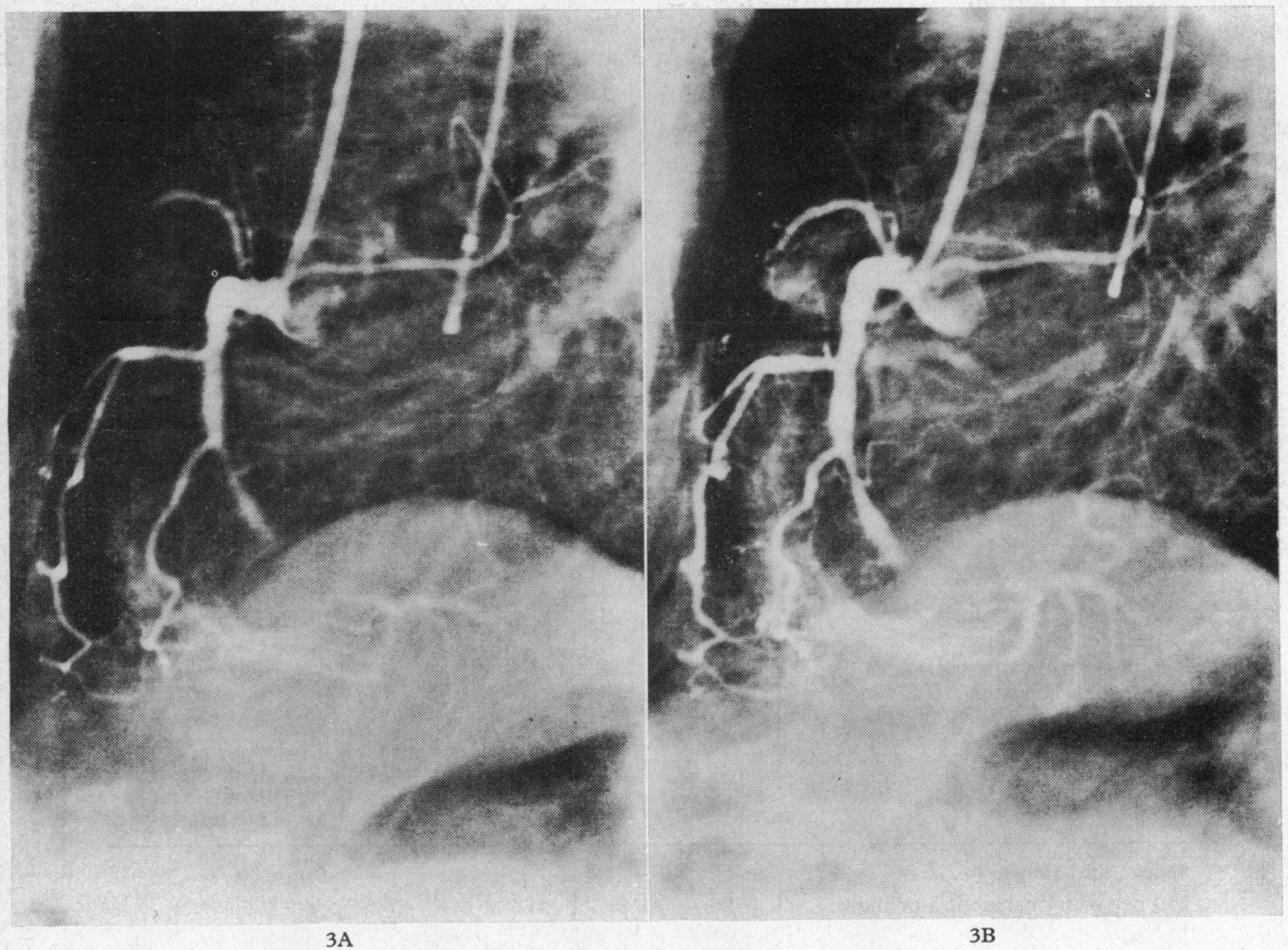


scending and right coronary arteries (Fig. 3) and 1 patient a widening of both the left anterior descending and left circumflex arteries. The clinical features are shown in Table 1 and the circulatory measurements in Table 2.

Nonresponders This group was the largest, comprising 16 patients, 49 per cent of those with collaterals. In 12 patients the collaterals were supplying segments distal to total occlusion, in 4 patients segments distal to 85 to 95 per cent stenosis. In 2 patients no asynergy was found. In 13 of the remaining 14 patients left ventricular asynergy was topographically related to the obstructions and collaterals. The collaterals were essentially unchanged during ischaemia. The pertinent data are shown in Tables 1 and 2.

Negative responders In 5 patients, 15 per cent of those with collaterals, these decreased during ischaemia. Three of the patients had total occlusions with distal segments supplied by collaterals; in 2 patients the obstructions were 90 and 95 per cent. One patient had a normal left ventricular contraction pattern; in 4 patients the left ventricular asynergy was related to the site of obstructions and collaterals. Three patients had class 3 collaterals decreasing to class 2,1 had class
2 collaterals decreasing to class 1 (Fig. 4), and 1 had class 1 collaterals not seen during ischaemia. One patient showed an additional narrowing of the right coronary artery during ischaemia. Clinical and circulatory data are shown in Tables 1 and 2.

One patient with total occlusions in the left anterior descending and right coronary arteries and a 90 per cent stenosis in the left circumflex artery had class 2 collaterals from the left circumflex to left anterior descending and right coronary arteries and class 3 collaterals from the right coronary to left anterior descending artery. Pacing to ischaemia resulted in increase in number and calibre of collaterals to the distal right coronary artery (inferior hypokinesia). Collaterals from the proximal right coronary to the left anterior descending decreased in calibre.

\section{Clinical and circulatory correlations}

The group with no prepacing collaterals differed in several respects from the patients with collaterals. There was no patient with total occlusion of any vessel and none had triple vessel disease. In only 3 was left ventricular asynergy observed. The mean coronary score was lower than that of any of the groups with collaterals $(P<0.001)$ and the heart volume was smaller $(P<0.01)$. Yet all had angina

TABLE 2 Circulatory measurements

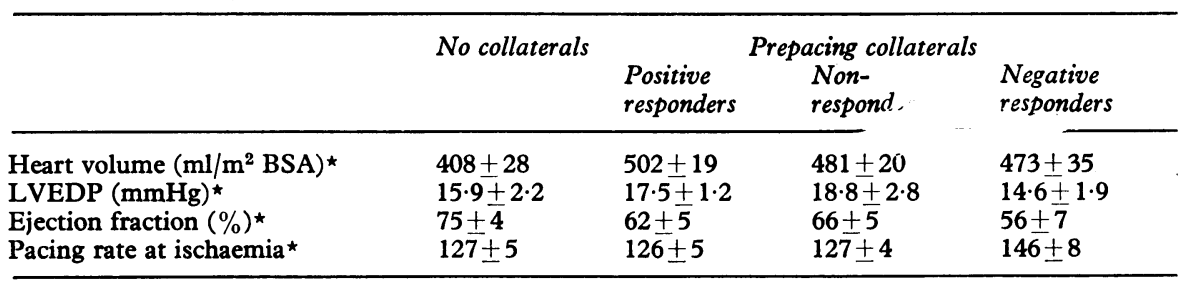

$\star M e a n \pm S E$ of the mean.

LVEDP, left ventricular end-diastolic pressure.

Conversion factor Traditional to SI units: $1 \mathrm{mmHg} \approx 0.133 \mathrm{kPa}$.

$\leftarrow \quad$ FIG. 2 A) Class 2 collaterals to distal right coronary artery in prepacing angiogram. B) Enhancement of collaterals to right coronary artery during ischaemia induced by pacing.

$\leftarrow \quad$ FIG. 3 A) Right coronary artery in prepacing angiogram. B) Widening of the right coronary artery during ischaemia induced by pacing. 


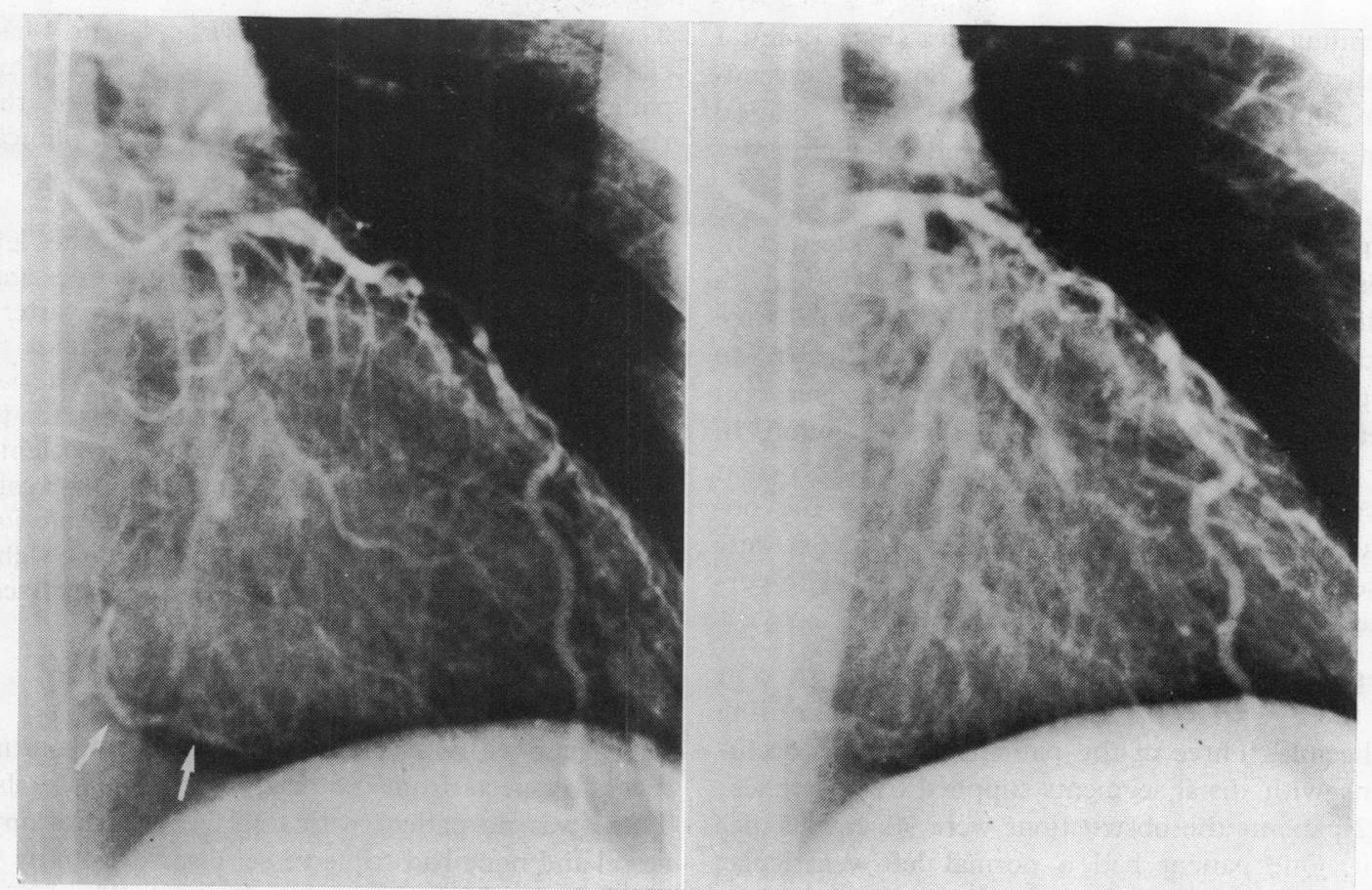

FIG. 4 A) Class 2 collaterals to distal right coronary artery in prepacing angiogram. B) Regression to class 1 during ischaemia induced by pacing.

pectoris and ischaemic ST segment changes during the maximal exercise test and were evaluated as candidates for coronary bypass surgery. The duration of angina pectoris was not shorter than that of the other groups (Table 1), and the LVEDP was similar. The ejection fraction, on the other hand, tended to be higher, in keeping with a greater number of patients with a normal contraction pattern of the left ventricle.

The groups with collaterals and different responses to ischaemia were fairly similar in their clinical and circulatory characteristics (Tables 1 and 2). The only difference was an increasing frequency of a history of previous myocardial infarction, from the positive responders through the nonresponders to the negative responders.

\section{Myocardial blood flow}

This was determined in 30 patients, 6 of whom belonged to the group with no prepacing collaterals. Four of the patients in this group exhibited a per-

TABLE 3 Myocardial blood flow

\begin{tabular}{|c|c|c|c|c|c|c|c|}
\hline & \multirow[t]{2}{*}{ No. of patients } & \multirow{2}{*}{\multicolumn{2}{|c|}{$\begin{array}{l}\text { Prepacing } \\
\quad \text { Cold } \\
\text { spot }\end{array}$}} & \multirow[b]{2}{*}{$\begin{array}{l}\text { Reference } \\
\text { areas }\end{array}$} & \multicolumn{3}{|c|}{ During ischaemia } \\
\hline & & & & & $\begin{array}{l}\text { Whole } \\
\text { image }\end{array}$ & $\begin{array}{l}\text { Cold } \\
\text { spot }\end{array}$ & $\begin{array}{l}\text { Reference } \\
\text { areas }\end{array}$ \\
\hline $\begin{array}{l}\text { No prepacing collaterals } \\
\text { Prepacing collaterals }\end{array}$ & 6 & $\begin{array}{l}55 \cdot 8^{\star} \\
\pm 7 \cdot 6\end{array}$ & $\begin{array}{l}51 \cdot 2 \dagger \\
\pm 5 \cdot 9\end{array}$ & $\begin{array}{l}60 \cdot 1 \\
\pm 11 \cdot 1\end{array}$ & $\begin{array}{l}65 \cdot 0 \\
\pm 13 \cdot 4\end{array}$ & $\begin{array}{l}59 \cdot 5 \dagger \\
\pm 16 \cdot 9\end{array}$ & $\begin{array}{l}65 \cdot 1 \\
\pm 16 \cdot 9\end{array}$ \\
\hline $\begin{array}{l}\text { positive responders } \\
\text { nonresponders } \\
\text { negative responders }\end{array}$ & $\begin{array}{r}10 \\
9 \\
4\end{array}$ & $\begin{array}{l}51 \cdot 3 \\
\pm 10 \cdot 1 \\
57 \cdot 7 \\
\pm 7 \cdot 8 \\
48 \cdot 3 \\
\pm 9 \cdot 1\end{array}$ & $\begin{array}{l}46.6 \\
\pm 11.5 \\
46.0 \\
+14.4 \\
53 \cdot 1 \\
\pm 13.9\end{array}$ & $\begin{array}{l}53 \cdot 7 \\
\pm 20 \cdot 3 \\
70 \cdot 3 \\
\pm 16 \cdot 5 \\
54 \cdot 1 \\
\pm 10 \cdot 6\end{array}$ & $\begin{array}{l}66 \cdot 2 \\
\pm 8 \cdot 8 \\
65 \cdot 0 \\
\pm 10 \cdot 3 \\
55 \cdot 0 \\
\pm 8 \cdot 3\end{array}$ & $\begin{array}{l}66 \cdot 4 \\
\pm 14 \cdot 2 \\
58 \cdot 5 \\
\pm 28 \cdot 4 \\
56 \cdot 5 \\
\pm 15 \cdot 3\end{array}$ & $\begin{array}{l}79 \cdot 4 \\
\pm 15 \cdot 0 \\
73 \cdot 1 \\
\pm 25 \cdot 9 \\
56 \cdot 9 \\
\pm 14 \cdot 3\end{array}$ \\
\hline
\end{tabular}

*Flow in $\mathrm{ml} / 100 \mathrm{~g}$ per $\min \pm \mathrm{SD}$. tOnly 4 patients. 
fusion defect in the scintigram, and all 24 patients with prepacing collaterals in which the scintigrams were made had a perfusion defect. The absolute values for flow before pacing and during ischaemia are given for the different groups in Table 3. The percentage changes caused by ischaemia in the four different areas used in the measurements are given for the various groups in Fig. 5. The data for the two areas in the vicinity of the defect were pooled.

The exceptional case with the bidirectional change showed an increase of 23 per cent for the whole imaged area and a similar increase for the areas in the proximity of the defect. The flow in the cold spot decreased by 5 per cent.

The myocardial flow of the whole heart responded to ischaemia by a mean increase of 29 per cent in the positive responder group, contrasting with the mean increase of 13 per cent in the nonresponder group and 14 per cent in the negative responder group. The difference between the positive responders and the pooled data of the non- and negative responders is significant $(P<0.05)$. The mean response of the group without prepacing collaterals was $+17 \cdot 0$ per cent.

The flow in the area of the perfusion defect increased in all groups, amounting to +43 per cent in the positive responder group. This did not differ significantly from the responses in the non- and negative responder groups, +27 per cent, and +6.5 per cent respectively, nor from the pooled data of the non- and negative responders. The group with no prepacing collaterals reacted to ischaemia by a mean increase of 16.0 per cent.

The positive responder group showed a mean increase of 48 per cent in the vicinity of the perfusion defect. This was superior to the response of +4 per cent in the nonresponders $(P<0.05)$ and +5.5 per cent in the negative responders $(P<0.05)$, and the pooled data of the non- and negative responders $(P<0.02)$. The group without collaterals responded by a mean increase of 8 per cent.

\section{Exercise tolerance}

The exercise tolerance data are shown in Table 4. The total work was somewhat lower in the group without prepacing collaterals, but this did not differ significantly from the total work in the other groups. The maximum tolerated load and maximum heart rate were similar in all groups except for the negative responses. Three of the 5 women belonged to the group without prepacing collaterals and may contribute to the slightly lower exercise tolerance. the maximum heart rates during physical exercise and during pacing were remarkably similar except in the group of negative responders.
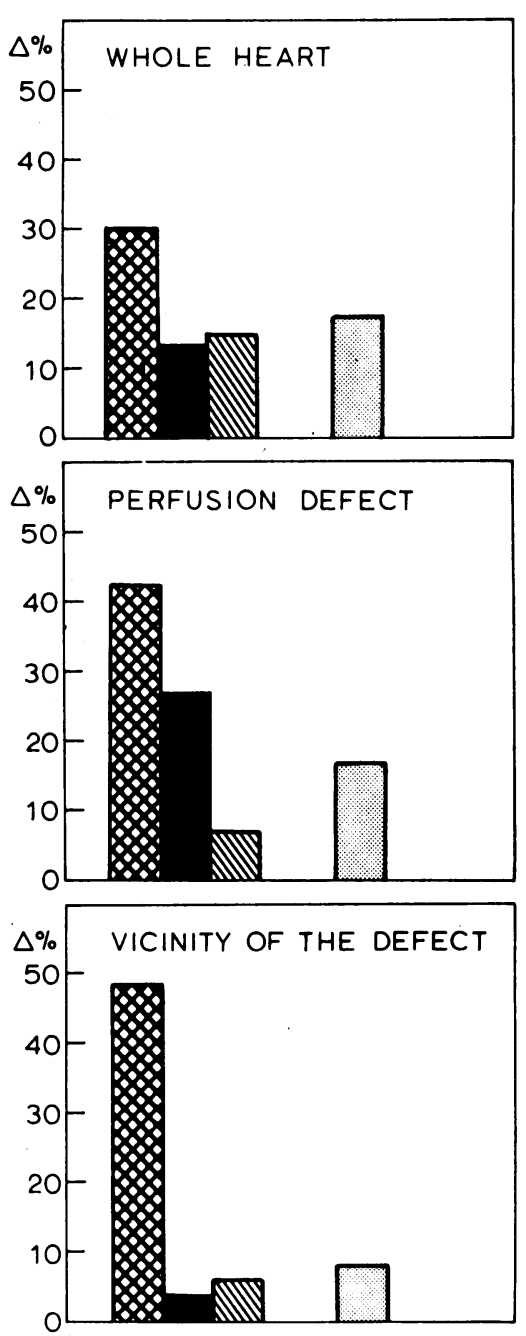

FIG. 5 Responses of the regional myocardial perfusion to ischaemia in relation to the collateral response. The columns represent from left to right: positive responders, nonresponders, negative responders, and the group without prepacing collaterals.

TABLE 4 Exercise tolerance

\begin{tabular}{llll}
\hline & $\begin{array}{l}\text { Total } \\
\text { work } \\
(\mathrm{kNm})\end{array}$ & $\begin{array}{l}\text { Maximal } \\
\text { load } \\
(\mathrm{kNm} / \mathrm{min})\end{array}$ & $\begin{array}{l}\text { Maximal } \\
\text { heart rate } \\
\text { (beats } / \mathrm{min})\end{array}$ \\
\hline $\begin{array}{l}\text { No collaterals } \\
\begin{array}{l}\text { Prepacing collaterals } \\
\text { positive responders } \\
\text { nonresponders } \\
\text { negative responders }\end{array}\end{array}$ & $\begin{array}{l}41 \cdot 9 \pm 11 \cdot 3 \\
32 \cdot 7 \pm 5 \cdot 3 \star 3\end{array}$ & $5 \cdot 3 \pm 0.7$ & $132 \pm 10$ \\
\hline
\end{tabular}

$\star=$ mean $\pm \mathrm{SE}$ of the mean 


\section{Discussion}

Attempts to establish the implications of the presence of coronary collaterals in ischaemic heart disease have been hampered by the varying severity of coronary atherosclerosis in the groups being compared. The general finding has been the absence of collaterals in patients with mild to moderate luminal obstructions, and this was corroborated in the present small series. This difficulty has been overcome by selecting groups with obstructions of equal severity but different collateral patterns (Helfant et al., 1971; Miller et al., 1971). Using this approach, coronary collaterals have been found to have no protective effect; on the contrary, myocardial ischaemia has been found to be more severe in patients with collaterals (Helfant et al., 1971), and an analysis of the prevalence of left ventricular asynergy has given similar results (Helfant et al., 1970; Miller et al., 1971). These data have been challenged by Levin et al. (1973), who concluded that collaterals are vital for preserving left ventricular function. More recent studies have not helped to resolve this difference of opinion. Carroll et al. (1974) found no correlation between the quality of collaterals and the number of abnormal left ventricular wall segments, whereas Banka et al. (1974) demonstrated with nitroglycerin that asynergic left ventricular wall segments which were supplied by collaterals exhibited higher residual contractile ability than segments without collateral supply. Collaterals were also found to have a protective effect on the occurrence of asynergy during static exercise (Handa et al., 1974).

The present study was undertaken to explore the dynamic nature of the visible collaterals. In a third of the patients with prepacing collaterals, these were increased by induced ischaemia. It is plausible to conclude that in these patients ischaemic vasodilatation increased the pre-existing pressure gradients favouring increased flow. The question of why this did not occur in all patients with prepacing collaterals is pertinent. One possibility is that the collaterals were already maximally dilated and carried flow to their maximal capacity before induction of ischaemia by pacing. It is more likely, however, that opposing forces were in operation. According to postmortem evidence the collaterals in ischaemic heart disease have a preference for intramural and endocardial locations (Schaper, 1971), though fairly large epicardial vessels are also frequently found at necropsy (James, 1970) and by angiography (Paulin, 1967). Ischaemia induced by atrial pacing is followed in a number of patients, but not in all, by an increase in LVEDP (Frick, 1972), decreasing the diastolic epicardial-endo- cardial pressure gradient and impeding especially the endocardial flow. In the absence of relevant pressure data this mechanism can only be inferred. It is also possible that the patients in the group of positive responders had more epicardial collaterals escaping the effect of rising LVEDP. A third possibility is that there is more fibrotic and scar tissue demanding less flow in patients with no response or a decrease in collaterals by ischaemia. This line of reasoning is supported by the higher prevalence of previous myocardial infarctions in these grousp (Table 1) but opposed by the almost equal ejection fractions (Table 2) and basal flow data (Table 3). There was also no difference between the groups in the anatomical distribution of the asynergic areas and their topographical relation to coronary arterial obstructions and collateral supply.

The concept that collateral flow in ischaemic heart disease is sufficient to maintain only resting energy requirements and is largely insensitive to vasodilatating procedures is based on the pioneering necropsy data of Blumgart et al. (1940) and the open-chest dog experiments of Kattus and Gregg (1959). The data of Goldstein et al. (1974) on the effect of nitroglycerin and the present findings indicate that human collateral circulation reacts to vasodilatation induced by either nitroglycerin or ischaemia. Direct intraoperative measurements of collateral flow in man have shown large increases after dipyridamole (M. H. Frick and P.-T. Harjola, 1975, unpublished observations). In normal man with healthy coronary arteries, right atrial pacing up to $130 / \mathrm{min}$ increases the myocardial flow by some 26 per cent (Knoebel et al., 1970). Right atrial pacing also increases myocardial flow in patients with coronary heart disease (Forrester et al., 1971), the magnitude of the increment depending on the responses in terms of ischaemia (Conti et al., 1970). Measurements of the regional myocardial blood flow in the present study revealed different increments, depending on the response of the collaterals to pacing-induced ischaemia (Fig. 5). A separation of the flow through anastomotic channels and through 'normal' coronaries cannot be made with the present data. However, the similarity of the coronary scores within the groups and the distinct differences in collateral responses to ischaemia afford suggestive evidence that the collaterals are intimately related to the increase in flow. Coronary spasm is occasionally observed in every catheterization laboratory, though not in the present series. The widening of large epicardial arteries in some of the patients during ischaemia shows that vasodilatory capacity is also preserved in some large arteries in ischaemic heart disease. 
The group with no prepacing collaterals included three patients with normal coronary arteries. In two of these a Xenon scintigram was made, and one showed a clearcut perfusion defect in the anterior wall. These patients, who had severe angina and a positive maximal exercise test, and were studied as candidates for coronary bypass surgery, presumably represent the subset of ischaemic heart disease in which the classical myocardial oxygen supplydemand mechanism is distorted, leading to unpredictable results of exercise testing and atrial pacing.

The similarity of the data on left ventricular function and exercise tolerance in the three groups, positive, non-, and negative responders, is evidence against the functional significance of the enhancement of collaterals by ischaemia. It is likely that there are no different subjective thresholds for the angina triggered by a large or small ischaemic area, and that angina in itself may be a manifestation of the run-off capacity of collateral circulation as suggested by Guyton (1971). The present data indicate, however, that collaterals are capable of increasing both their size and the amount of flow in response to an appropriate stimulus. The patient with bidirectional response to ischaemia illustrates that internal adjustments occur, evidently favouring areas with greater demands. A 'stealing' effect (Fuster et al., 1974) could not be studied since the contralateral coronary artery was not routinely injected during ischaemia. Though there is evidence that collaterals significantly reduce the mortality in acute myocardial infarction (Williams et al., 1974), and normal values for regional myocardial perfusion under basal conditions have been observed distal to obstructions if well supplied by collaterals (Cannon, Dell, and Dwyer, 1972), the present data suggest that the ability of collaterals to meet the increased metabolic demands of pacing or exerciseinduced tachycardia is limited. The disappearance of collaterals after successful bypass grafting (Valle et al., 1975), and the correlation of this phenomenon with improved exercise tolerance after surgery (Frick, Harjola, and Valle, 1975) do not contradict this argument, but are the result of a changed distribution of effective pressure gradients.

\section{References}

Banka, V. S., Bodenheimer, M. M., and Helfant, R. H. (1974). Determinants of reversible asynergy. Effect of pathologic $Q$ waves, coronary collaterals, and anatomic location. Circulation, 50, 714.

Baroldi, G., Mantero, O., and Scomazzoni, G. (1956). The collaterals of coronary arteries in normal and pathologic hearts. Circulation Research, 4, 223.
Bloor, C. M., and Liebow, A. A. (1965). Coronary collateral circulation. American fournal of Cardiology, 16, 238.

Blumgart, H. L., Schlesinger, M. J., and Davis, D. (1940). Studies on the relation of the clinical manifestations of angina pectoris, coronary thrombosis, and myocardial infarction to the pathological findings. American Heart Fournal, 19, 1.

Cannon, P. J., Dell, R. B., and Dwyer, E. M., Jr. (1972). Regional myocardial perfusion rates in patients with coronary artery disease. fournal of Clinical Investigation, 51, 978.

Carroll, R. J., Verani, M. S., and Falsetti, H. L. (1974). The effect of collateral circulation on segmental left ventricular contraction. Circulation, 50, 709.

Conti, C. R., Pitt, B., Gundel, W. D., Friesinger, G. C., and Ross, R. S. (1970). Myocardial blood flow in pacinginduced angina. Circulation, 42, 815.

Demany, M. A., Tambe, A., and Zimmerman, H. A. (1967). Correlation between coronary arteriography and postexercise electrocardiogram. American fournal of Cardio$\log y, 19,526$.

Forrester, J. S., Helfant, R. H., Pasternac, A., Amsterdam, E. A., Most, A. S., Kemp, H. G., and Gorlin, R. (1971). Atrial pacing in coronary heart disease: effect on hemodynamics, metabolism and coronary circulation. American fournal of Cardiology, 27, 237.

Frick, M. H. (1972). Right atrial pacing in coronary heart disease. Advances in Cardiology, 8, 193.

Frick, M. H., Harjola, P.-T., and Valle, M. (1975). Effect of aorto-coronary grafts and native vessel patency on the occurrence of angina pectoris after coronary bypass surgery. British Heart founral, 37, 414.

Frick, M. H., Heikkilä, J., and Luomanmäki, K. (1970). Pressure responses to left ventricular and aortic angiography characterizing incipient left ventricular failure. In Incipient Cardiac Insufficiency, p. 111. Sandoz, Basle.

Frick, M. H., Valle, M., Wiljasalo, M., and Korhola, $O$. (1974). Coronary angiography during pacing-induced ischemia: a new approach to the collaterals. Methodological aspects. Annals of Clinical Research, 6, 253.

Frick, M. H., Virtanen, K., and Sävelä, J. (1972). Modification of digitalis-induced electrocardiographic changes by propranolol and potassium. Annals of Clinical Research, 4, 213.

Fulton, W. F. M. (1965). The Coronary Arteries. Thomas, Springfield, Illinois.

Fuster, V., Frye, R. L., Connolly, D. C., Danielson, M. A., and Mankin, H. T. (1974). Electrocardiographic-angiographic correlation and its influence by collaterals early in the onset of the coronary syndromes (abstract). Circulation, 50, Suppl. 3, 108.

Gensini, G. G., and Da Costa, B. C. B. (1969). The coronary collateral circulation in living man. American fournal of Cardiology, 24, 393.

Goldstein, R. E., Stinson, E. B., Scherer, J. L., Seningen, R. P., Grehl, T. M., and Epstein, S. E. (1974). Intraoperative coronary collateral function in patients with coronary occlusive disease. Circulation, 49, 298.

Guyton, A. C. (1971). Collaterals, blood flow and tissue nutrition. New England fournal of Medicine, 284, 1323.

Handa, S., Flessas, A., Connelly, G., Klein, M., Keefe, J., and Ryan, T. (1974). Ventricular asynergy during static exercise: its relation to coronary lesions and collateral vessels (abstract). Circulation, 50, Suppl. 3, 51.

Helfant, R. H., and Gorlin, R. (1972). The coronary collateral circulation. Annals of Internal Medicine, 77, 995.

Helfant, R. H., Kemp, H. G., and Gorlin, R. (1970). Coronary atherosclerosis, coronary collaterals, and their relation to cardiac function. Annals of Internal Medicine, 73, 189. 
Helfant, R. H., Vokonas, P. S., and Gorlin, R. (1971). Functional importance of the human coronary collateral circulation. New England fournal of Medicine, 284, 1277.

Herman, M. V., Heinle, R. A., Klein, M. D., and Gorlin, R. (1967). Localized disorders in myocardial contraction. Asynergy and its role in congestive heart failure. New England fournal of Medicine, 277, 222.

James, T. N. (1970). The delivery and distribution of coronary collateral circulation. Chest, 58, 183.

Jonsell, S. (1939). A method for the determination of the heart size by teleoroentgenography (a heart volume index). Acta Radiologica, 20, 325.

Kattus, A. A., and Gregg, D. E. (1959). Some determinants of coronary collateral blood flow in the open-chest dog. Circulation Research, 7, 628.

Knoebel, S. B., Elliott, W. C., Ross, E., and McHenry, P. L. (1970). The effect of cardioacceleration by right atrial pacing on myocardial blood flow in normal human subjects. Cardiovascular Research, 4, 306.

Korhola, O. (1974). Myocardial scintigraphy and estimation of regional blood flow with Xenon-133. Acta Radiologica, Suppl. 337.

Korhola, O., Valle, M., Wiljasalo, M., Riihimäki, E., Suoranta, H., and Frick, M. H. (1975). Myocardial perfusion defects in ischemic heart disease visualized by semiselective ${ }^{133} \mathrm{Xe}$ injections. Correlations with left ventricular angiography. Fournal of Nuclear Medicine and Biology. (In the press.)

Lavine, P., Filip, Z., Najmi, M., Kimbiris, D., Segal, B. L., and Linhart, J. W. (1974). Clinical and hemodynamic evaluation of coronary collateral vessels in coronary artery disease. American Heart fournal, 87, 343.

Levin, D. C., Sos, T. A., Lee, J. G., and Baltaxe, H. A. (1973). Coronary collateral circulation and distal coronary runoff: the key factors in preserving myocardial contractility in patients with coronary artery disease. American fournal of Roentgenology, 119, 474.

Lewis, R. P., and Sandler, H. (1971). Relationship between changes in left ventricular dimensions and the ejection fraction in man. Circulation, 44, 548.

Martinez-Rios, M. A., Da Costa, B. C. B., Cecena-Seldner, F. A., and Gensini, G. G. (1970). Normal electrocardiogram in the presence of severe coronary artery disease. American fournal of Cardiology, 25, 320.

Miller, R. R., Mason, D. T., Salel, A., Zelis, R. F., Massumi, R. A., and Amsterdam, E. A. (1972). Determinants and functional significance of the coronary collateral circulation in patients with coronary artery disease (abstract). American fournal of Cardiology, 29, 281.

Miller, R. R., Zelis, R., Mason, D. T., and Amsterdam, E. A. (1971). Relation of coronary collateral vessels to ventricular function in patients with equal extent of coronary artery disease (abstract). Circulation, 44, Suppl. 2, 202.

Moberg, C. H., Webster, J. S., and Sones, F. M. (1972). Natural history of severe proximal coronary disease as defined by cineangiography (abstract). American fournal of Cardiology, 29, 282.

Paulin, S. (1967). Interarterial coronary anastomoses in relation to arterial obstruction demonstrated in coronary arteriography. Investigative Radiology, 2, 147.

Schaper, W. (1971). The Collateral Circulation of the Heart. North-Holland, Amsterdam.

Sowton, G. E., Blacon, R., Cross, D., and Frick, M. H. (1967). Measurement of the angina threshold using atrial pacing. A new technique for the study of angina pectoris. Cardiovascular Research, 1, 301.

Tuna, N., and Amplatz, K. (1970). The significance of coronary collateral circulation. Coronary arteriographic and electrovectorcardiographic correlations (abstract). American fournal of Cardiology, 26, 663.

Valle, M. (1973). Postoperative coronary angiography. Acta Radiologica, Suppl. 333.

Valle, M., Wiljasalo, M., Frick, M. H., Korhola, O., Suoranta, H., and Tallorth, K. (1975). Collateral circulation before and after coronary reconstruction. Annals of Clinical Research, 7, 251.

Williams, D. O., Amsterdam, E. A., Hughes, J. L., Miller, R. R., and Mason, D. T. (1974). Importance of coronary collaterals in acute myocardial infarction: relation to pump function, cardiogenic shock and survival (abstract). Circulation, 50, Suppl. 3, 108.

Zoll, P. M., Wessler, S., and Schlesinger, M. J. (1951). Interarterial coronary anastomoses in the human heart, with particular reference to anemia and relative cardiac anoxia. Circulation, 4, 797.

Requests for reprints to Dr. M. H. Frick, Cardiovascular Laboratory, First Department of Medicine, University Central Hospital, Haartmaninkatu 4, 00290 Helsinki 29, Finland. 